\title{
DEVELOPMENT OF EMOTIONAL COMPETENCE IN EXAM SITUATIONS WITH STUDENTS WHO ACHIEVE DIFFERENT ACADEMIC SUCCESS AND STUDY DIFFERENT STUDY PROGRAMS
}

\author{
Zlatko Pavlović ${ }^{1}$ \\ Sonja Kaurin ${ }^{2 i}$, \\ Biljana Sladoje-Bošnjak ${ }^{3}$ \\ ${ }^{1}$ Faculty of Philosophy, \\ University of East Sarajevo, \\ Bosnia and Herzegovina \\ 2Faculty of Philosophy, \\ University of East Sarajevo, \\ Bosnia and Herzegovina \\ ${ }^{3}$ Faculty of Philosophy, \\ University of East Sarajevo, \\ Bosnia and Herzegovina
}

\begin{abstract}
:
The authors, in the theoretical part of the paper, define and explain the concept of emotional competence, as well as skills that should be developed and strengthened within the mentioned concept. Also, the importance of emotional competence in exam situations for the academic success of students has been presented, which is supported by the presentation of research related to this topic. The aim of the study was to examine whether students with different academic achievement and from different study programs showed different levels of emotional competence in exam situations. The research was conducted on a sample of 115 students from the Faculty of Philosophy, University of East Sarajevo. The paper presents the results of examining the differences in the development of emotional competence in exam situations in students with different academic achievement and the results of examining the differences in the development of emotional competence in students in exam situations depending on the study program they study. The findings show that there are no differences in the development of emotional competence in exam situations in students with different academic achievement, but there are differences when it comes to the development of emotional competence in exam situations depending on the study program that students' study. This research is a contribution to a better understanding of students' emotional competencies in exam situations and may have practical implications in terms of
\end{abstract}

i Correspondence: email sonja.kaurin@ff.ues.rs.ba 
understanding the importance of improving the emotional sphere in all study programs by expanding study objectives so that they include developing of students' emotional competencies.

Keywords: emotional competence, academic success, study program, exam situations

\section{Introduction}

In previous studies and research, the term emotional intelligence has been used most often. The term emotional intelligence did not appear until the 1990s, and was founded by Mayer and Salovey (J. D. Mayer \& P. Salovey). In the scientific literature, they also gave the first definition of emotional intelligence, saying that it includes "the ability to quickly observe, evaluate, express emotions; recognizing and generating feelings that facilitate thinking; understanding emotions and knowledge about emotions, and the ability to regulate emotions in order to promote emotional and intellectual development" (Mayer, Salovey, 1997, p.10). Many authors use other terms when talking about emotional intelligence, ie. set of skills and abilities, so in the literature we have the terms emotional literacy (Goleman, 2001) and emotional competence (Takšić, Mohorić, Munjas, 2006). There are also those who equate the terms emotional intelligence and emotional competence. From a theoretical point of view, it makes sense to equate the terms emotional intelligence and emotional competence (Salovey, Slayter, 1997). However, we believe that emotional intelligence is a prerequisite for the development of emotional competence. Emotional intelligence is the core ability and knowledge of emotions, and emotional competence occurs when someone reaches a certain level of emotional achievement. For this reason, the term emotional competence has been introduced, which is more focused on the knowledge and abilities that an individual can achieve in order to function normally in different situations. According to Steiner (2003), the term emotional competence refers to the ability to understand one's own emotions, the ability to listen to others and empathy, and the ability to express emotions productively. Goleman (1995) states that emotional competence is the ability to know and recognize one's own feelings, as well as the feelings of others, the ability to self-motivate, to manage emotions in oneself and in relationships with others.

From the above we can conclude that emotional competence is the formation of a person through the processes of emotional activity, which is a set of properties of a person's identity and includes emotional knowledge, skills of emotional activity, abilities shown in this activity. Emotional competence is also understood as the ability to process information contained in emotions, defining the value of emotions, their interrelationships and using emotions as a basis for thinking and making decisions (Mayer, Salovey, Caruso, 2004). Emotional competence allows us to be content with ourselves and the world around us. It can be developed, ie. it is educational in nature. The skills that make up emotional competence and that need to be developed and strengthened in a social environment are: 
1. Awareness of one's own emotional states, including the ability to experience multiple emotions, and at more mature levels, awareness that due to unconscious dynamics or selective inattention one does not have to be aware of one's own feelings.

2. Ability to perceive other people's emotions on the basis of situational or expressive signals that have a certain degree of cultural consensus on their emotional significance.

3. Ability to use the vocabulary of emotions and expressions available in one's (sub)culture, and at more mature levels, the ability to adopt cultural scenarios that connect emotion with social roles.

4. Ability to empathize with other people's emotional experiences.

5. The ability to understand that the internal emotional state does not necessarily correspond to external expression, both in us and in others, and at more mature levels, the ability to understand that one's emotional-expressive behavior may affect others, and the ability to take this into account in one's own selfpresentation strategies.

6. Ability to adjust control over arrogant or uncomfortable feelings using selfregulatory strategies that amplify the intensity or duration of such emotional states.

7. Awareness that the nature of relationships is partly determined by the quality of emotional communication within those relationships.

8. Ability for emotional self-efficacy: the individual feels that, overall, he/she feels the way he/she wants to feel (Saarni, 1999, p.5).

All of the listed abilities or skills are dynamic and interdependent. The general goal of emotional competencies learning is to understand and control our own emotions, to process emotions in a way that will harmonize us with reality, other people and enable us to creatively express and realize our own potentials. In developed emotional competencies, the key to better mental health, setting personal goals, improving learning and better academic success is increasingly seen.

Academic success is a determinant of progress in the education system. It is the outcome of education, ie the measure by which students, professors and higher education institutions have achieved their educational goals. There are different definitions of academic success, and one of them is that it is success on standardized knowledge tests, and the measure of academic success is the average grade during studies (Kalechstein, Nowick, 1997).

Academic intelligence has long been considered necessary for academic success. Namely, emotional competence is also important for success, because a man is not only an intellectual, but also an emotional being. According to the results of some research, emotional competence can help individuals stand out through life transitions starting from school to college. At the faculty level, emotional competence is considered a valuable skill that helps students cope with academic demands (Mohzan, Hassan, Abd Halil, 2013). 
Taking the exam is an inseparable part of student life, and the results achieved at the exam and in general during the studies have a great impact on the development of the individual, on the development of his/her emotional competence, self-confidence and self-efficacy. Exam situations for most students are stressful during their studies and educational process. The intensity of stress in exam situations depends on how student considers success in the exam important. If a student considers the exam, he/she is taking important and is satisfied with how he/she has done it, he/she will feel proud. Emotions experienced in exam situations can help students achieve academic goals and have a positive effect on his/her subjective benefit (Burić, Sorić, Penezić, 2011). From this we can see that test situations can also evoke positive emotions, such as hope, happiness, pride that act activating and they increase motivation and achievement. But emotions, such as helplessness, can also be destructive, deactivating (Burić, Sorić, Penezić, 2011). There are two types of processes during the test situation that are emotion-oriented and can be deactivating, and these are fantasy and self-blame. Imagination involves the appearance of thoughts such as that a miracle will happen and he/she will pass the exam, while selfblame refers to criticizing oneself for insufficient preparation or a poorly done test. These thoughts can negatively affect the success of students on the test (Schutz et al., 2004). The special importance of experiencing and regulating emotions refers to taking exams, so the authors suggest three dimensions of emotion regulation in exam situations:

1) Task-oriented processes: if the student thinks about effective answering strategies or the economical use of the time, he/she has left during the exam, he/she increases the chances of better success.

2) Emotion-oriented processes: redirecting thoughts from the task to oneself, to the emotions that the student experiences because of his/her achievement. These thoughts can be disruptive and reduce chances of success.

3) Cognitive assessment processes: the student assesses the importance of the test and his/her own abilities to master it (Schutz et al., 2006).

There are numerous studies that have linked emotional intelligence or emotional competence to students' academic success. According to the research of Takšić et al. (Takšić, Štokalo, Kolić-Vehovec, 2002), academic success can be explained by emotional competence. More emotionally competent students achieve better success, and thus those students with better success show a higher degree of emotional competence. Also, in a series of researches, the connection of emotions with academic achievement has been determined, where positive emotions such as joy, hope, pride contribute to high achievements (Pekrun et al., 2002). Research results at the Faculty of Education in Malaysia (Universiti Teknologi Mara UiTM, Shah Alam, Selangor, Malaysia) show that students have a high level of emotional intelligence. However, no significant relationship has been found between emotional intelligence and academic achievement (Mohzan, Hassan, Abd Halil, 2013). Emotionally competent students demonstrate culturally accepted ways of expressing emotions, which may include masking or minimizing emotions, or replacing one emotion with another. They can recognize beneficial emotions and retain them, amplify or intensify them, while at the same time inhibiting less 
productive emotions and the negative behaviors that result from them through strategies such as seeking support, reshaping problems, solving problems, or distractions.

Emotional competence in exam situations, as we can see in all of the above, determines how successfully we can use all the abilities we possess to overcome challenging and frustrating situations such as taking exams. If taking the exam is seen as a step towards achieving the goal, the student will be motivated to learn, thus achieving better results which leads to greater self-confidence and awakening of positive emotions in exam situations, and thus to more developed emotional competence.

\section{Material and methods}

The research has been conducted in students of the Faculty of Philosophy, University of East Sarajevo, with the aim of examining whether students with different academic success and from different study programs show different levels of emotional competence in exam situations. In accordance with the set goal, research tasks have been formulated:

1) to examine differences in the development of emotional competence in test situations in students who achieve different academic success.

2) to examine the differences in the development of students' emotional competence in exam situations depending on the study program they study.

Research hypotheses:

1) it is assumed that there are differences in the development of emotional competence in test situations in students who achieve different academic success.

2) it is assumed that there are differences in the development of emotional competence of students in exam situations depending on the study program they study.

\subsection{Variables}

The research has included three variables: the academic success of students, the study program they study and their assessment of their own emotional competence in test situations.

\subsection{Methods}

The methods used are: the method of theoretical analysis and the descriptive (survey) method.

\subsection{Research techniques}

The techniques used in the research are the survey technique and the scaling technique. The survey technique has been applied to collect general data about the respondents, such as: gender, academic success, year of study, study program. The scaling technique is based on an assessment scale, and has been used to assess one's own emotional competence in test situations. 


\subsection{Research instruments}

The instrument used in the research is the scale of Emotional Competence of students in exam situations. This scale is a five-point Likert-type scale constructed for the purposes of this research. The items in the scale have been selected to form a representative sample of emotional competence in the test situations. There are 15 items. All items relate to the assessment of one's own emotional competence in test situations. Examples of some items from the Emotional Competence scale of students in exam situations are: It happens that I tremble when taking an exam; I feel proud to know that I did a good test; During the exam, I just think about when the exam will end; When I get scared I have a hard time remembering the answer to the exam question. Students have assessed their own emotional competence in exam situations by having the opportunity to indicate, with each statement on a five-point scale, how much the offered statement applies to them by choosing numbers from 1 to 5 (1- not at all, 2-mostly not, 3-from time to time, 4-mostly yes and 5-completely yes). The reliability of the Student's Emotional Competence scale in test situations was checked via the Cronbach's alpha coefficient. In the original version of the instrument, we had 22 items. Then the value of the Cronbach's alpha coefficient was $\alpha=0,795$. After we found that certain items were low and negatively correlated with other items on the scale, we eliminated 7. There were 15 items left and we did reliability again, so the value of the Cronbach's alpha coefficient was $\alpha=0,833$. The stated value of the Cronbach's alpha coefficient indicates satisfactory reliability and stability of the scale of Emotional Competence of students in test situations.

\subsection{Sample}

The sample for this research consists of students of the Faculty of Philosophy, University of East Sarajevo. The sample includes 115 students from different study programs, namely: Pedagogy, Psychology, Mathematics and Computer Science, Philological Science and Political Science.

The structure of the sample with respect to the gender of the students is shown below.

Table 1: Sample structure with respect to student gender

\begin{tabular}{lcc}
\hline Gender & Frequencies & Percentages \\
\hline Male & 51 & $44,3 \%$ \\
\hline Female & 64 & $55,7 \%$ \\
\hline Total & 115 & $100,0 \%$ \\
\hline
\end{tabular}

In the following table we can see the structure of the sample with respect to the study program that the students study.

Table 2: Sample structure with respect to the study program

\begin{tabular}{lcc}
\hline Study program & Frequencies & Percentages \\
\hline Pedagogy & 25 & $21,7 \%$ \\
\hline Psychology & 22 & $19,1 \%$ \\
\hline
\end{tabular}




\begin{tabular}{lcc}
\hline \hline Mathematics and Computer Science & 21 & $18,3 \%$ \\
\hline Philological Sciences & 24 & $20,9 \%$ \\
\hline Political Sciences & 23 & $20,0 \%$ \\
\hline Total & 115 & $100,0 \%$ \\
\hline
\end{tabular}

\subsection{Research organization and data processing procedures}

The research was realized in August 2020. For the needs of this research, and in accordance with the studied research problem and the methods used, research procedures enabling the presentation of the obtained results and their analysis were applied. Among the statistical procedures, the following were used: one-factor analysis of variance and descriptive statistics (frequencies, percentages).

\section{Results and discussion}

\subsection{Differences in the development of emotional competence in exam situations in} students with different academic success

Emotional competence as the ability to understand, express and manage emotions is important for different learning outcomes. Students experience a wide range of emotions during lectures and in exam situations. Depending on whether the emotions are positive or negative, they can either improve learning success or hinder the learning process, and thus lead to poorer academic success. In the following table we can see the results of a one-factor analysis of variance related to the assessment of emotional competence of students with different academic success.

Table 3: Analysis of the variance of scores achieved on the scale for assessing emotional competence in exam situations by students of different academic success

\begin{tabular}{lccccc}
\hline Source of variability & The sum of the squares & df & Variance & F & P \\
\hline Between groups & 491,665 & 3 & 163,888 & 2,188 &, 093 \\
\hline Within groups & 8314,456 & 111 & 74,905 & \\
\hline Total & 8806,122 & 114 & & \\
\hline
\end{tabular}

The homogeneity of the variances has been checked by the Lavene test. The value of Lavene statistics is $0,396(p=0,756)$, which confirms the homogeneity of variance. From Table 3 we can see that the value is $p=0,093$, which shows us that there is no difference in the development of emotional competencies in exam situations in students of different academic success. We expected students with better academic performance to have more developed emotional competencies, however, this research did not confirm our hypothesis. The lack of differences in the development of emotional competencies in exam situations in students with different academic success may indicate the fact that the academic success that students achieve is more conditioned by other variables compared to emotional competencies in exam situations. Of course, the possibility of the factor of giving socially desirable answers by the respondents should also be taken into account. 
A study conducted by Takšić et al. (2002) concluded that academic success could be explained by emotional competence. The results of their research showed that more emotionally competent students achieved better success, and thus those students with better success showed a higher degree of emotional competence. This would mean that perhaps at younger ages that connection is present, and then at older ages it weakens. Also, a number of studies have found the connection between emotions and academic achievement, where positive emotions such as joy, hope, pride contribute to high achievements (Pekrun et al., 2002).

Although grades are most often used in research as an indicator of students' academic success, they serve not only as an indicator of knowledge and ability, but also as means of motivation. We took general success during studies as a measure of academic success. Such an indicator depends on a large number of different factors, which could also have influenced the results we obtained. It is probable that more precise indicators of the links between academic success and emotional competence could be obtained if, instead of general success in studies, narrower and more concrete indicators were considered as a measure of student success, e.g. results on standardized knowledge tests.

\subsection{Differences in the development of emotional competence in students in exam situations depending on the study program they study}

Emotional competencies are recognized as a vital element in many educational institutions, including colleges. Science has repeatedly confirmed that emotions are not opposed to rationality, but are part of it. Emotions deeply affect the academic engagement of students, and the development of emotional competencies in exam situations may determine the academic success of students, the choice of a later occupation, ie. study program. Table 4 shows the results of a one-factor analysis of variance achieved by students from different study programs on the scale for assessing emotional competence in test situations.

Table 4: Analysis of the variance of scores achieved by students from different study programs on the scale for assessing emotional competence in exam situations

\begin{tabular}{lccccc}
\hline Source of variability & The sum of the squares & df & Variance & F & P \\
\hline Between groups & 1082,496 & 4 & 270,624 & 3,854 &, 006 \\
\hline Within groups & 7723,626 & 110 & 70,215 & \\
\hline Total & 8806,122 & 114 & & \\
\hline
\end{tabular}

The homogeneity of the variances has been checked by the Lavene test. The value of Lavene statistics is $0,665(p=0,618)$, which confirms the homogeneity of variance. Insight into the results we obtained using one-factor analysis of variance shows that there is a statistically significant difference in the development of emotional competencies in students in exam situations depending on the study program they study, and this confirms the value $\mathrm{p}=0,006$. 
Table 5 shows the results of testing individual differences between arithmetic means achieved by students from different study programs on the scale of emotional competence in test situations.

Table 5: LSD test results

\begin{tabular}{|c|c|c|c|c|}
\hline $\begin{array}{l}\text { (I) } \\
\text { Study program }\end{array}$ & $\begin{array}{l}\text { (J) } \\
\text { Study program }\end{array}$ & $\begin{array}{c}\text { Difference of arithmetic } \\
\text { means (I-J) }\end{array}$ & $\begin{array}{c}\begin{array}{c}\text { Standard } \\
\text { error }\end{array} \\
\end{array}$ & $\mathbf{P}$ \\
\hline \multirow[t]{4}{*}{ Pedagogy } & Psychology & 3,97636 & 2,44952 & ,107 \\
\hline & Mathematics and Computer Sciences & $8,36381^{*}$ & 2,48035 & 001 \\
\hline & Philological Sciences & 2,54833 & 2,39462 & ,290 \\
\hline & Political Sciences & $7,23130^{*}$ & 2,42103 & , 003 \\
\hline \multirow[t]{4}{*}{ Psychology } & Pedagogy & $-3,97636$ & 2,44952 & 107 \\
\hline & Mathematics and Computer Sciences & 4,38745 & 2,55639 & , 089 \\
\hline & Philological Sciences & $-1,42803$ & 2,47330 & , 565 \\
\hline & Political Sciences & 3,25494 & 2,49888 & , 195 \\
\hline \multirow{4}{*}{$\begin{array}{l}\text { Mathematics } \\
\text { and Computer } \\
\text { Sciences }\end{array}$} & Pedagogy & $-8,36381^{*}$ & 2,48035 & ,001 \\
\hline & Psychology & $-4,38745$ & 2,55639 & , 089 \\
\hline & Philological Sciences & $-5,81548^{*}$ & 2,50383 & ,022 \\
\hline & Political Sciences & $-1,13251$ & 2,52911 & ,655 \\
\hline \multirow{4}{*}{$\begin{array}{l}\text { Philological } \\
\text { Sciences }\end{array}$} & Pedagogy & $-2,54833$ & 2,39462 & ,290 \\
\hline & Psychology & 1,42803 & 2,47330 & ,565 \\
\hline & Mathematics and Computer Sciences & $5,81548^{*}$ & 2,50383 & ,022 \\
\hline & Political Sciences & 4,68297 & 2,44508 & ,058 \\
\hline Political & Pedagogy & $-7,23130^{*}$ & 2,42103 & ,003 \\
\hline \multirow[t]{3}{*}{ Sciences } & Psychology & $-3,25494$ & 2,49888 & ,195 \\
\hline & Mathematics and Computer Sciences & 1,13251 & 2,52911 & ,655 \\
\hline & Philological Sciences & $-4,68297$ & 2,44508 & ,058 \\
\hline
\end{tabular}

Note: ${ }^{*}$ The difference is significant at the 0.05 level.

In Table 5 we can see that there are statistically significant differences between groups of students studying Pedagogy, Mathematics and Computer Sciences and Political Science, as well as differences between students studying Mathematics and Computer Sciences and Philological Sciences. These differences could be viewed from the aspect of belonging to the social sciences, humanities or natural sciences. The social sciences and humanities deal with issues of a man, the development of human society, ideas that shape human life, human values, and therefore in these sciences more attention is paid to the development of the emotional sphere in students. At the same time, the natural sciences are exact, they are only interested in the areas they deal with, and the dimension of emotional development and the development of emotional competencies in students is not included in the natural sciences such as mathematics. Through studies, Pedagogy students deal with emotional development of a person, development and strengthening of emotional competencies through various workshops, so in Graph 1 we see that in Pedagogy students, according to their self-assessments, emotional competencies are the most developed, and in Mathematics and Computer Sciences students the least developed. 


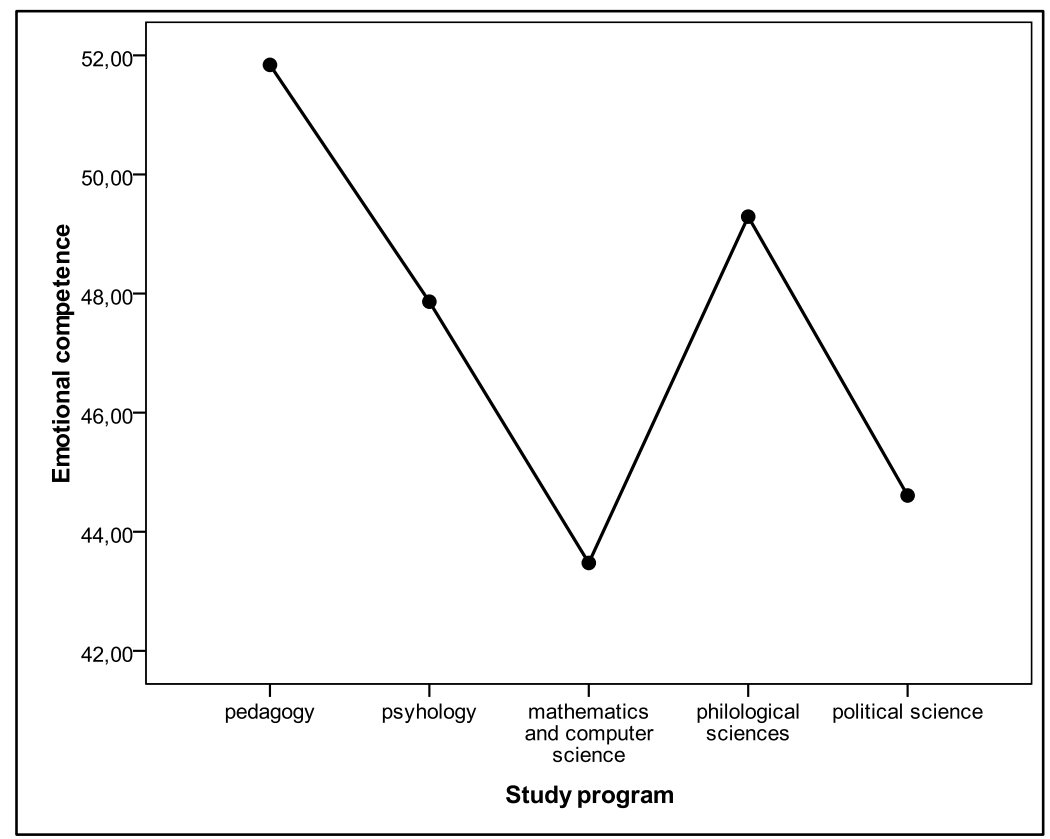

Graph 1: Arithmetic means of scores achieved on the scale for assessing emotional competence in exam situations by students from different study programs

Also, from Graph 1 we can see that students of Philological Sciences show a high degree of maturity and development of emotional competencies in exam situations. Students of Political Science evaluate low their own emotional competencies in exam situations and such results can be attributed to the field which this study deals in. In other words, students of Mathematics and Computer Sciences and Political Science are significantly below the level of development of emotional competencies in exam situations shown by students of Pedagogy and Philological Sciences on the scale for assessing emotional competencies in exam situations. We can say that they have the ability to understand, control, express and use the emotions that guide them through the study process. The study program of Psychology does not show differences compared to other study programs, so in Graph 1 we can see that students of Psychology have quite developed emotional competencies in exam situations, which is logical given the nature of their future occupation. Although the differences in the assessment of competencies among psychology students have not shown a statistically significant difference compared to other groups, it is still noticeable that they are closer to students of pedagogy and philological sciences. These results suggest that the development of emotional competencies should be an important element of the curricula at the faculties. The teaching process should be based on the motivation for the course, on the emotions of students, on their attitudes and beliefs about the course, so that we would harmonize the intellectual and emotional aspects during teaching, and students would feel intellectually and emotionally more mature and competent towards greater self-confidence in test situations. 


\section{Recommendations}

It is necessary to prepare students for the teaching profession and various types of cooperation with the social environment, not only intellectually, but to work on instilling and developing skills of emotional competence through certain activities and modules. The process of implementing the concept of emotional competence in teaching could take place through awareness of the importance of emotional factors for educational work, primarily among teachers, who would transfer this awareness to students through various creative activities. Especially if we take into account the animosity of students towards the course of mathematics, the need and importance for the development of emotional competencies in students of mathematics, future teachers of mathematics is recognized. Given that emotional competencies are educational in nature and develop from emotional activities, then we see the need to organize a course (compulsory or elective) in the curriculum for the Study Program of Mathematics and Computer Science or to organize workshops, courses, etc. When it comes to students of Political Science, the introduction of such courses and listening to lectures in the field of emotional competencies, would open opportunities for the development of a different discourse in the field of political science than usual. It would refer to the introduction of more empathy and tolerance in communication, as well as the support of other emotional abilities. We believe that the area of emotional competence in the teaching process is insufficiently researched and leaves a lot of room for further research and creation of programs that would bring the educational process to a higher level. Emotional improvement is one of the ways to move into the future of better educational work.

\section{Conclusion}

The results we obtained suggest that self-assessments of emotional competence do not differ in students who achieve different academic success. Thus, our first research hypothesis was not confirmed. Depending on the study program that students' study, we recorded differences in the development of emotional competence in test situations, and the second research hypothesis was confirmed.

The obtained results indicate the existence of links between the study profile, ie the profession for which students are preparing, and some indicators of their emotional competencies (specifically, emotional competencies in exam situations). Also, students whose studies are related to socio-humanistic areas assess their emotional competencies more positively than students whose studies are related to natural-technical areas. The result obtained for students studying Political sciences, which belong to the social sciences, and whose results are closer to students of natural and computer sciences, differs somewhat from such a picture. We can assume that the registered connections are multi-layered. On the one hand, the differences are already manifested in the choice of studies regarding greater focus on people and human relations or on mathematics and technology, and on the other hand, during studies, the further development of 
competencies in the emotional sphere is encouraged to varying degrees. Thus, the development of these competencies is more encouraged in those students who, during their studies, acquire knowledge and skills in the field of human nature and interpersonal relationships. All this can then contribute to the existence of differences in different emotional competencies, even in those that are manifested in test situations. The possibility that at least a part of the obtained differences is conditioned by different sensitivity for their own emotional states in students from different study programs should not be neglected either. It is possible that students from social sciences and humanities have more developed introspective abilities to better assess the level of their own emotional competencies in different situations including exams as well.

\section{Conflict of Interest Statement}

The authors declare no conflicts of interests.

\section{About the authors}

Zlatko Pavlović was born in 1967 in Sanski Most (Bosnia and Herzegovina). He studied pedagogy and psychology in Sarajevo. He works as a professor of pedagogy at the Faculty of Philosophy, University of East Sarajevo. He deals with general pedagogical issues of the nature of education and problems of school learning.

Sonja Kaurin is a master of pedagogy, employed as a senior assistant at the Department of Pedagogy, Faculty of Philosophy, University of East Sarajevo. She has written and published several papers in the field of General Pedagogy.

Biljana Sladoje-Bošnjak, a full professor of pedagogy, is employed at the Faculty of Philosophy, University of East Sarajevo. She was born in 1976 in Sarajevo. The scientific field he deals with is the methodology of scientific research, and within it, research projects are of special importance.

\section{References}

Burić, I., Sorić, I., Penezić, Z. (2011). Strategije emocionalne regulacije u ispitnim situacijama: Doprinosi osobina ličnosti, kognitivnih procjena i ispitnih emocija./ Emotional regulation strategies in test situations: Contributions of personality traits, cognitive assessments, and test emotions. Psihologijske teme/Psychological topics, 20 (2), 277-298.

Goleman, D. (1995). Emotional intelligence. Bantam Books.

Goleman, D. (2001). Emotional intelligence: Issues in paradigm building. In C. Cherniss \& D. Goleman (Eds.), The Emotionally Intelligent Workplace, (pp. 13-26), Jossey-Bass: San Francisco.

Kalechstein, A. i Nowick, S. Jr. (1997). A meta-analytic examination of the relationship between control expectancies and academic achievement: an 11-year follow-up to Findley and Cooper. Genetic, Social and General Psychology Monographs, 123, 29-57. 
Mayer, J. D., Salovey, P. (1997). What is emotional intelligence? In P. Salovey \& D. J. Sluyter (Eds.), Emotional development and emotional intelligence: Educational implications (p. 3-34). Basic Books.

Mayer, J. D., Salovey, P., Caruso, D. R. (2004). Emotion intelligence: Theory, findings, and implication. Psychological Inquiry, 15(3), 197-215.

Mohzan, M. A. M., Hassan, N., Halil, N. A. (2013). The Influence of Emotional Intelligence on Academic Achievement, Procedia - Social and Behavioral Sciences 90, 303-312. doi: 10.1016/j.sbspro.2013.07.095

Pekrun, R., Goetz, T., Titz, W., \& Perry, R. P. (2002). Academic emotions in students' selfregulated learning and achievement: A program of qualitative and quantitative research. Educational Psychologist, 37(2), 91105. https://doi.org/10.1207/S15326985EP3702 4

Saarni, C. (1999). A Skill-Based Model of Emotional Competence: A Developmental Perspective. Symposium Emotion Management in Interpersonal Relationships: Converging Evidence and Theoretical Models, New Mexico: 1-20.

Salovey, P., Sluyter, D. J. (Eds.). (1997). Emotional development and emotional intelligence: Educational implications. Basic Books.

Schutz, P.A., DiStefano, C., Benson, J., Davis, H. A. (2004). Developing a measure of emotion regulation during test taking. Anxiety, Stress and Coping, 17, 253-269.

Schutz, P. A., Hong, J. Y., Cross, D. I., Osbon, J. N. (2006). Reflections on investigating emotion in educational activity settings. Educational Psychology Review, 18, 343-360.

Steiner, C. (2003). Emotional Literacy: Intelligence with a Heart. USA: Personhood Press.

Takšić, V., Štokalo, V., Kolić-Vehovec, S. (2002). Prognostička valjanost emocionalne inteligencije (kompetentnosti) za uspjeh u školi/ Prognostic validity of emotional intelligence (competence) for school success. Psihologijske teme/Psychological topics, 11, 81-90.

Takšić, V., Mohorić, T., Munjas, R. (2006). Emocionalna inteligencija: operacionalizacija i povezanost sa pozitivnom psihologijom/ Emotional intelligence: operationalization and connection with positive psychology. Društvena istraživanja: časopis za opća društvena pitanjal Social Research: A Journal for General Social Issues, 15 (4-5), 729-752. 

will be applied to their work. Under the terms of this license, no permission is required from the author(s) or publisher for members of the community to copy, distribute, transmit or adapt the article content, providing a proper, prominent and unambiguous attribution to the authors in a manner that makes clear that the materials are being reused under permission of a Creative Commons License. Views, opinions and conclusions expressed in this research article are views, opinions and conclusions of the author(s). Open Access Publishing Group and European Journal of Education Studies shall not be responsible or answerable for any loss, damage or liability caused in relation to/arising out of conflicts of interest, copyright violations and inappropriate or inaccurate use of any kind content related or integrated into the research work. All the published works are meeting the Open Access Publishing requirements and can be freely accessed, shared, modified, distributed and used in educational, commercial and non-commercial purposes under a Creative Commons Attribution 4.0 International License (CC BY 4.0). 